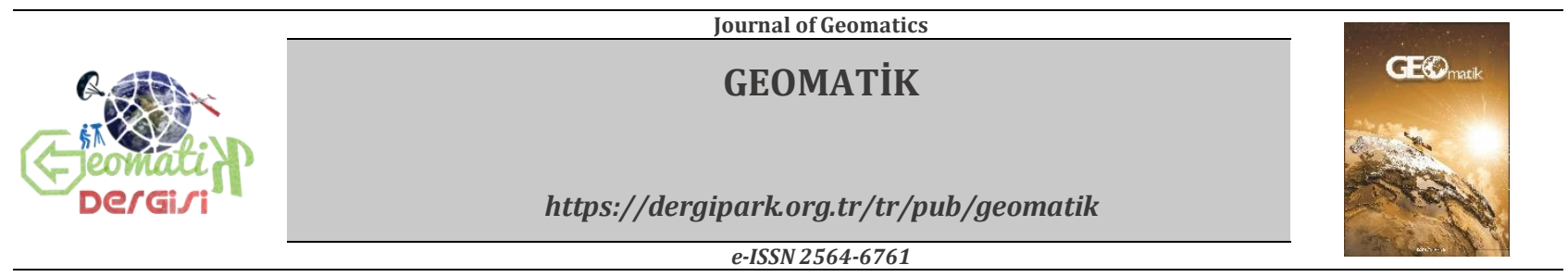

\title{
Uydu Görüntüsü İşleme ve Sıkıştırma Süreçlerinin WEB Tabanlı Harita Servisi Yayın Performansına Etkilerinin Araştırılması
}

\author{
Zafer DURKUT ${ }^{* 1}$, Uğur ALGANCI ${ }^{2}$, Elif SERTEL ${ }^{2}$ \\ 1İstanbul Teknik Üniversitesi, Bilişsim Enstitüsü, İstanbul, Türkiye \\ 2İstanbul Teknik Üniversitesi, Geomatik Mühendisliği Bölümü, İstanbul, Türkiye
}

\author{
Anahtar Kelimeler \\ Web tabanlı harita servisi \\ Veri sikıştırma \\ JPEG \\ WMS standardı \\ SPOT-7 \\ Sentinel-2 \\ Landsat-8
}

\begin{abstract}
ÖZ
Günümüzde gelișen uydu teknolojilerine bağlı olarak uydu görüntülerinin mekânsal, spektral ve zamansal çözünürlügünde önemli seviyede artışlar meydana gelmiştir. Bu artışlar aynı zamanda veri boyutunda ve hacminde artıșa ve buna bağı olarak veri paylaşımında zorluklara sebep olmaktadır. Artan veri boyutları, web üzerinden coğrafi verilerin paylaşımını ve sunumunu da zorlaştırmaktadır. Bu problemlerin çözümüne yönelik yöntemlerden biri olan uydu görüntülerinin sıkıştırılması, veri boyutunun azaltılmasını sağlayan bir optimizasyon yöntemidir. Bu çalışmada Landsat-8, Sentinel-2 ve SPOT-7 uydularından elde edilen çok bantlı uydu görüntülerinin sıkıștırılmasında uluslararası bir standart olan JPEG sıkıştırma algoritmasının web tabanlı cografi veri yayını kapsamında performansının değerlendirilmesi hedeflenmiştir. Ek olarak uydu görüntülerinin WMS tabanlı sunum performansını arttırmak amacıyla sıkıștırılmış görüntüler üzerinde piramitleme işlemi yapılmıștır. Bu çalışmada, farklı çözünürlükteki uydu görüntülerine dört farklı sıkıștırma seviyesi ve dört farklı piramit seviyesi için JPEG formatında sıkıştırma uygulanmış; sonuçlar işleme süresi, görsel kalite ve veri boyutu açısından karşılaştırılmıştır. Ayrıca elde edilen sonuç verileri coğrafi veri sunucusu üzerinden sunularak web üzerindeki yayın performansları belirlenmiştir. Çalıșma sonuçlarına göre yüksek sıkıştırma ve piramit seviyesi ile yüksek performanslı ve düşük veri hacimli veri yayını yapılabileceği görülmektedir.
\end{abstract}

\section{Investigating the Effects of Image Processing and Compressing Steps on the Performance of Web Mapping Services}

\author{
Keywords \\ Web mapping service data \\ Compression \\ JPEG \\ WMS standard \\ SPOT-7 \\ Sentinel-2 \\ Landsat-8
}

\begin{abstract}
There has been a significant increase in the spatial, spectral and temporal resolution of satellite images due to the developing satellite technologies. These increases also result in an increase in data size and volume, and hence data sharing difficulties. Increased data sizes also make it difficult to share and present geographic data over the web. Compressing satellite images is one of the solutions to these problems, which offers an optimization by reducing data size. In this study, it is aimed to evaluate the performance of JPEG compression algorithm, which is an international standard, in the context of web based spatial data broadcasting in order to compress multi-band satellite images obtained from Landsat-8, Sentinel-2 and SPOT-7 satellites. In addition, pyramid levels were added on the compressed images in order to enhance the WMS-based presentation performance of satellite images. In this study, four different JPEG compression levels and four different pyramid levels were applied on satellite images with different spatial resolution. The results were compared in terms of processing time, visual quality and data size. In addition, the resulting data was presented on the geographic data server and the broadcast performance on the web was determined. According to the results of the research, high performance and low data volume data can be broadcast with high compression and pyramid level.
\end{abstract}




\section{GíRiş}

Son yillarda gelișen bilgisayar, telekomünikasyon ve bilişim teknolojilerine bağlı olarak artan veri hacmi ve veriye erişim ihtiyaçlarından dolayı web tabanlı bilgi servislerinin kullanımı artmıştır. Web servisleri farklı donanımların ağ üzerinden etkileşiminden faydalanarak bu donanımların birlikte çalışmalarını sağlamaktadır. Microsoft, Oracle, IBM, HP, Sun ve daha birçok firma web servisleri konusunda çalışarak yazılım ve uygulama desteği sunmaktadır. Web tabanlı mekânsal veri servisleri ile coğrafi bilgi sitemlerinin yetenekleri birleştirildiğinde sunulan hizmet daha efektif olmaktadır (Smiatek, 2004; Michealis ve Ames,2008).

Web üzerinden coğrafi verilerin sunulması amacıyla OGC tarafından çeșitli standartlar geliştirilmiştir. Bu çalışmada uydu görüntülerinin sunulması amacıyla Web Harita Servis (WMS) standartları kullanılmıştır (OGC, 2016). WMS mimarisinin temel amacl, mekânsal referans bilgisi barındıran coğrafi verilerin dinamik haritalarını üretmektir. Bu kapsamda WMS standardı, coğrafi verilerin bir bilgisayar ekranında görüntülenmeye uygun dijital görüntü dosyası olarak sunumunu esas almaktadır. WMS servislerinde coğrafi verilerin HTTP yolu ile istemciye aktarımı için PNG, JPEG, GIF vb. dijital görüntü formatları kullanılmaktadır. Ayrıca WMS dahilinde belirlenen tanımlamalar, haritaların istemciler tarafından talep edilme şeklini ve sunucuların tanımlanma şeklini standartlaştırır (Kim vd., 2005; Panagos vd.,2008).

INSPIRE ilkelerinde, veri ve hizmetlerin birlikte çalışabilirliğini sağlamak amacı ile uluslararası kurum ve kurulușların harita sunucularında bulunan veri katmanlarının WMS standartlarına uygun şekilde üretilmesi ve paylaşılması benimsenmiştir (INSPIRE, 2007).

Özellikle son yıllarda uydu teknolojilerinde meydana gelen gelişim ve çözünürlük artışına bağlı olarak yer gözlem uydularından elde edilen görüntülerin mekânsal veri olarak kullanımında artış meydana gelmiştir. Bu artışa bağlı olarak uydu görüntülerinin web tabanlı yayını kapsamında da önemli gelişmeler meydana gelmiştir. Google Maps ve BingMaps gibi uygulamalar küresel ölçekte ve çeşitli çözünürlükte uydu görüntü verisi katmanı yayını yapan en bilindik uygulamalar olarak karşımıza çıkmaktadır. Bunun dışında birçok kurum ve kuruluş kendi kullanım amaçlarına yönelik olarak işledikleri hava fotoğrafı ve uydu verisi vb. raster verileri web tabanlı servisler aracılığ kullanıcılara sunmaktadır (Hatzopoulos vd., 2012). Ülkemiz özelinde yakın zamanda yayına açılan HGM Atlas platformu bu duruma en uygun örneklerden birisidir.

Uydu verilerinin web tabanlı sunumu esnasında karşılaşılan en temel problemlerden ilki mekânsal çözünürlükte ve paylaşılan görüntü sayısında meydana gelen artışa bağlı olarak veri hacminin büyümesidir. Buna ek olarak verinin belirli yaklașma seviyelerindeki ön görünümlerinin eklenmesi ile veri boyutu daha da artmaktadır. $\mathrm{Bu}$ artış hem depolama alanı problemi yaratmakta hem de verinin sunucudan istemciye transferi esnasında veri trafiği yükünü artırmaktadır. $\mathrm{Bu}$ problemi çözüme kavuşturmak ve yayın optimizasyonunu sağlamak amacı ile sıkıştırmalı resim formatlarının kullanımı yaygınlaşmıștır (Millin ve Kimito, 2007).

$\mathrm{Bu}$ çalışmada, farklı çözünürlüklü uydu görüntüleri üzerinde uygulanan farklı JPEG sıkıştırma ve piramitleme seviyelerinin veri boyutu üzerindeki etkisi ve web tabanlı harita servislerindeki performansı araştırılmıştır. Buna ek olarak farklı arazi örtüsü karakteristiklerinin ve kapsama alanının yayın performansı üzerindeki etkileri de değerlendirilmiştir.

\section{YÖNTEM}

\subsection{Veri}

$\mathrm{Bu}$ çalışma kapsamında beş farklı veri seti kullanılmıştır. $\mathrm{Bu}$ veriler SPOT-7, Sentinel-2 ve Landsat-8 uydu görüntülerinden elde edilen görünür bölgeye ait üç bantlı doğal renk kombinasyonlarını içermektedir.

Görüntüler sırasıyla 1,5 m, 10 m ve 30 m olmak üzere üç farklı mekânsal çözünürlüğe sahiptir. Tablo-1'de çalışmada kullanılan ham uydu görüntülerinin, çözünürlük, görüntü ve veri boyutları, Şekil 1'de ise ön izlemeleri verilmiştir. Birinci veri seti aynı bölgeyi kapsayan 3 farklı uydu görüntüsü içermekte olup mekânsal çözünürlüğün web tabanlı harita servisi üzerindeki etkisini belirlemek için kullanılmıștır. İkinci veri seti İzmir ve Şanlıurfa illerine ait SPOT-7 görüntülerini içermekte olup, farklı arazi örtüleri ile sıkıștırma ve piramitleme yöntemleri arasındaki ilişkiyi ortaya koymak amacı ile çalışmaya dahil edilmiştir. Üçüncü veri seti ise Adıyaman ve Şanlıurfa illerini kapsayan mozaiklenmiş SPOT-7 uydu görüntüsü olup, veri boyutundaki artışın web tabanlı coğrafi veri yayınına etkisini belirlemek amacı ile kullanılmıştır. Sonuç olarak üç farklı performans karşılaştırması için beș adet uydu görüntü veri seti kullanılarak farklı sıkıştırma ve piramitleme seviyelerinin web yayınına etkisi araştırılmıştır.

Tablo 1. Çalıșmada kullanılan uydu görüntüleri ile ilgili detaylar

\begin{tabular}{lllll}
\hline Bölge & Uydu & $\begin{array}{l}\text { Çözünürlük } \\
(\mathrm{m})\end{array}$ & $\begin{array}{l}\text { Görüntü Boyutu } \\
\text { (Piksel) }\end{array}$ & $\begin{array}{l}\text { Veri } \\
\text { Boyutu } \\
(\mathrm{MB})\end{array}$ \\
\hline GAP & SPOT-7 & 1,5 & $106701-90840$ & 27732,5 \\
İzmir & SPOT-7 & 1,5 & $42916-43802$ & 5378,8 \\
Urfa & SPOT-7 & 1,5 & $41198-44750$ & 5275,3 \\
Urfa & Landsat-8 & 30 & $2071-2237$ & 13,3 \\
Urfa & Sentinel-2 & 10 & $6214-6714$ & 121,8 \\
\hline
\end{tabular}




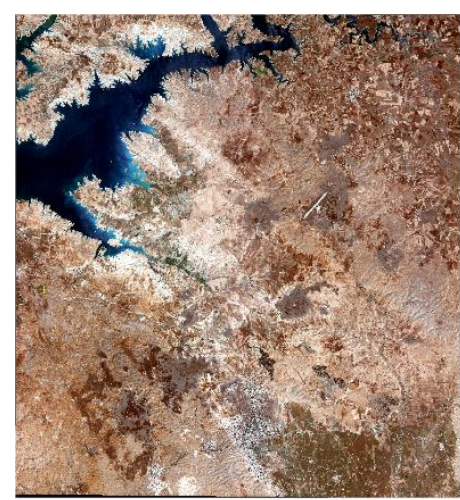

Spot-7 Şanlıurfa

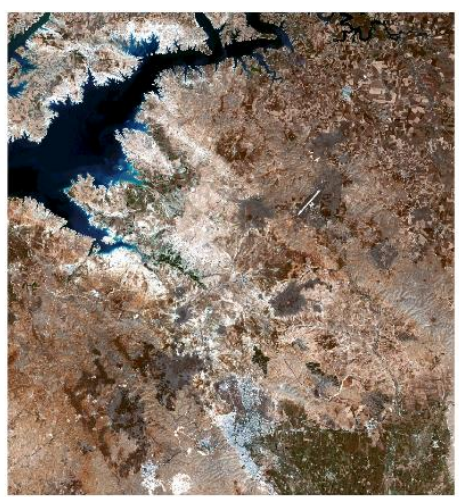

Sentinel-2 Şanlıurfa

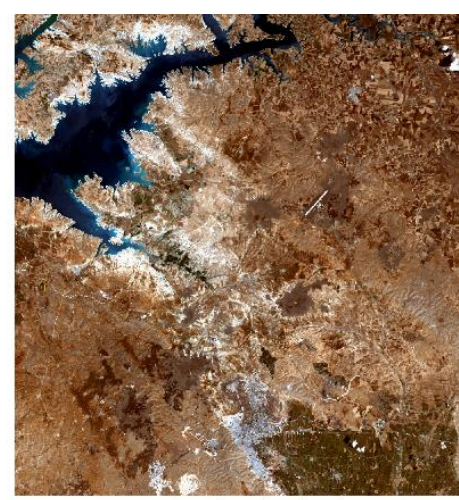

Landsat Şanlıurfa

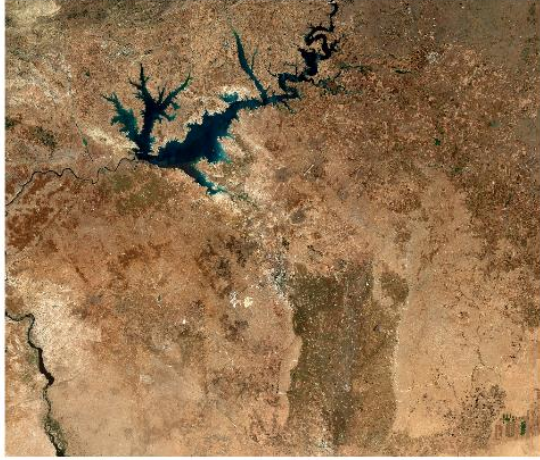

Spot-7 GAP

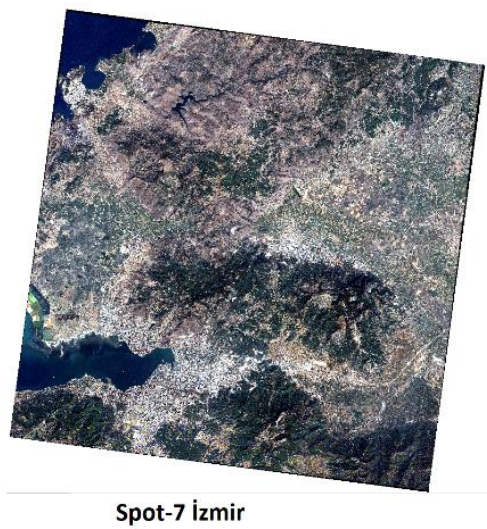

Spot-7 İzmir

Şekil 1. Çalışmada kullanılan uydu görüntülerinin ön izlemeleri

\subsection{Uygulama}

Uydu görüntülerinin sıkıștırılması ve piramit yapılarının oluşturulması aşamaları, 4 Core Intel Core i7 2600K işlemci, DDR3 8 GB ram özelliklerine sahip donanım üzerinde yapılmıștır. Çalıșma Python programlama dili kullanılarak gerçekleștirilmiștir. Çalışmada kullanılan algoritmalar, coğrafi verilerin işlenmesini sağlayan GDAL (Geospatial Data Abstraction Library) kütüphanesi yardımıyla hazırlanmıștır. Çalışmada görsel kaliteyi mümkün olduğunca yüksek tutarak veri boyutunu minimum düzeye indirebilecek bir sıkıştırma yöntemi seçilmesi hedeflenmiştir. Bu nedenle, literatürde yaygın kullanıma sahip olan ve yüksek düzeyde sıkıştırma sağlayan JPEG sıkıştırma yöntemi seçilmiştir. Sıkıştırma seviyesinin, sıkıştırma kalitesi, veri boyutu ve yayın performansına etkilerini tespit etmek amacıyla beş farklı sıkıştırma seviyesi ve beş farklı görüntü kalitesi seçilmiştir. Görüntü kalite seviyeleri sırası ile $\% 60, \% 70, \% 80, \% 90$ ve $\% 100$ olarak belirlenmiştir. Mevcut görüntü kalitesini yüksek düzeyde tutmayı sağlamak amacıyla görüntü kalitesi \%60'ın üzerinde seçilmiştir.

Kaydırma boyutu (blocksize), uydu görüntülerinin sıkıștırılması esnasında görüntüde sıkıștirılacak olan birim alanın boyutunu ifade etmekte olup, mevcut algoritma içerisinde yer alan bir parametredir. Bu çalışmada kaydırma boyutu, 128, 256 ve 512 piksel olarak seçilmiş ve her bir değerin sıkıștırma boyutu, süresi ve performansına etkileri gözlenmiștir.
Sıkıştırma işlemi tamamlanan görüntülerde WMS performansını arttırmak amacıyla piramitleme işlemi yapılmaktadır. Piramitleme işlemi, belirlenen yakınlaştırma seviyeleri için belirlenen düzeyde ana görüntüden alt örneklenmiş yeni görüntüler üreterek ve bu alt örneklenmiş görüntüleri sıkıștırılmış görüntü üzerine ekleyerek görüntülerin daha hızlı görselleştirilmesini sağlamaktadır. $\mathrm{Bu}$ çalışmada altıncı seviyeden dokuzuncu seviyeye olmak üzere dört adet alt örneklenmiş piramit seviyesi kullanılmıștır. Çalışmada piramit üretiminin altıncı seviyeden başlatılmasının nedeni, yayın performansının yüksek seviyelerde oluşan büyük veri hacmi altında test edilmesi hedefidir.

Çalışmada kapsamında beş adet görüntü için beş farklı sıkıştırma kalitesi, üç farklı kaydırma boyutu ve dört farklı piramit seviyesi parametre kombinasyonuna karşıllk gelen 300 adet görüntü hazırlanan yazilım ile üretilmiştir. Üretimi gerçekleşen her bir görüntü açık kaynak kodlu coğrafi veri sunucusu olan Geoserver yazilımı içerisine aktarılmış ve web tabanlı veri yayını gerçekleştirilmiştir. Coğrafi veri yayını yapan sunucunun teknik özellikleri 64 Core AMD Opteron ${ }^{\text {TM }}$ Processor 6380 işlemci ve 256 GB RAM şeklindedir. Coğrafi veri sunucusunda bulunan görüntülerin web yayını performansını tespit etmek amacıyla Linux tabanlı Apache Benchmark yazılımı kullanılmıştır. Performans ölçütleri olarak sunucunun bir saniyede cevap verebildiği istek sayısı ve bir dakika sürede aktarılan kilobayt cinsinden veri miktarı parametreleri seçilmiştir. Sunucuya WMS servisi ile 
yapılan istekler 900 x 900 piksel boyutunda olup istek yapılan görüntünün tamamını kapsamaktadır. Performans testi için belirlenen seçenekler ile üretimi yapılan her bir görüntü üzerinde anlık olarak 10 kullanıcı için kullanıcı başına 100 istek gönderilmek sureti ile toplamda 1000 istek yapılmıștır.

Performans testi için seçilen anlık kullanıcı sayısı ve istek miktarı sunucunun donanımsal yapısı göz önünde bulundurularak, yükleme testi esnasında çok sayıda isteğe aynı anda ve hatasız cevap verebileceği koşullar dahilinde seçilmiştir.

Analiz kapsamında çalışmada kullanılan ham görüntüler ve işlenmiş görüntüler için toplamda 305 bin istek yapılmış olup hatalı istek ortaya çıkmadan performans testi tamamlanmıștır. Performans testi sonuçları, sıkıştırma işlemi ve piramitleme işlemleri sonuçları ile birlikte değerlendirilebilecek şekilde standartlaştırılarak yorumlanabilir hale getirilmiştir.

\section{BULGULAR}

Çalışma kapsamında üretilen 300 adet görüntü için toplam sıkıștırma süresi 1034.2 dakika ve toplam piramitleme süresi 1908.8 dakika olarak ölçülmüştür. Bununla birlikte sıkıştırma işleminde toplam 508.8 GB boyutunda ve piramitleme işleminde toplam 980.0 GB boyutunda veri işlenmiştir. Üretilen görüntülerin Geoserver coğrafi veri sunucusu üzerinden yayınlanıp, Apache Benchmark yazılımı ile her bir görüntü için 900x900 piksellik alanı kapsayan 1000 istek ile toplamda 305 bin hatasız istek yapılarak coğrafi veri yayını performans testi tamamlanmıştır.

Sonuçlara göre kaydırma boyutu (blocksize) parametresinin sıkıştırma boyutu, piramitlenmiş görüntü boyutu ve yayın performansına kayda değer bir ektisi olmadığı gözlemlendiğinden sonuç analizlerinde göz ardı edilmiş ve kaydırma boyutu 256 olarak seçilmiştir. Yapılan çalışmada veri sayısı ve veri sayısına bağlı olarak üretilen grafiklerin fazla olmasından dolayı 9. seviye veri kümesine ait grafikler sunulmuştur. Diğer seviyelerin grafiklerine URL1'den çevrimiçi olarak ulaşılabilmektedir. Çalışma kapsamında üretilen grafiklerde $\% 60, \% 80$, \%100 sıkıştırma seviyesine ait sonuçlar gösterilmiştir. Grafikler üzerinde gösterilen boyut değişimi, sıkıştırma ile piramitleme işlemi sonrasında oluşan veri boyutunun ham veriye oranından elde edilen yüzdelik değerdir. Bu bağıl değer işlemler sonrasında ham veride meydana gelen boyut değişimini ifade etmektedir.

Çalışmada birinci veri seti aynı bölgeyi kapsayan 3 farklı uydu görüntüsü içermekte olup çözünürlüğün web tabanlı harita servisi üzerindeki etkisini ortaya koymayı amaçlamıştır. Karşılaştırma sonucunda Şanlıurfa iline ait aynı kapsama alanı için Spot-7, Sentinel-2, Landsat-8 uydu görüntüleri için sıkıștırma süresi, piramitleme süresi, boyuttaki değişim, saniyede yanıt verilen istek sayısı ve dakikada aktarılan veri miktarı olarak beș adet parametreye göre kıyaslama sonuçları Şekil.2'de grafik olarak verilmektedir. Grafikte satır isimlendirmesi sırasıyla uydu adı, bölge adı ve sıkıștırma kalitesi olarak olușturulmuștur. Sütün değerleri birimsiz olup lejantta verilen birimlere göre değerlendirme yapılmıştır. Grafik incelendiğinde aynı bölgeye ait üç uydu görüntüsü için mekânsal çözünürlük arttıkça sıkıştırma ve piramitleme süresinin arttığı gözlemlenmiştir.

Veriler performans olarak karşılaştırıldığında 9. piramit seviyesi için çözünürlük arttıkça yayın performansında düşüş olduğu gözlenmiştir. Her uydu görüntüsü kendi içinde incelendiğinde sıkıștırma seviyesi arttığında sıkıştırma süresi ve piramitleme süresi ve bununla birlikte boyuttan kazanç oranı artmıștır.

İkinci veri seti İzmir ve Şanlıurfa illerine ait SPOT-7 görüntülerini içermekte olup, farklı arazi örtüleri ile sıkıştırma ve piramitleme yöntemleri arasındaki ilişkiyi ortaya koymayı amaçlayan çalışmada dokuzuncu piramit seviyesi için üretilen grafik Şekil.3'te verilmektedir. Şekil.2 ile aynı lejanta sahip olan Şekil.3'te boyut değişimi göze alındığında sıkıştırma seviyesi 100 için aynı çözünürlüğe sahip olmasına rağmen İzmir bölgesi için yüzde 8.4 boyut kazancı varken Şanlıurfa bölgesi için boyut kazancı $\% 25,4$ 'dür.

$\mathrm{Bu}$ karşılaştırma göz önüne alındığında farklı arazi örtülerinin veri boyutu üzerinde etkisi olduğu tespit edilmiştir. Her iki bölge verisi için sıkıştırma seviyesi arttığında sıkıștırma süresi ve piramitleme işlem süresi artmıştır. Yayın performans açısında bakıldığında iki verinin saniyedeki yanıt verebildiği istek sayısı yaklaşık olarak aynıdır. $\mathrm{Bu}$ veriler özelinde farklı arazi örtülerinin boyut üzerinde yaklaşık \%17 etkisi varken yayın performansı üzerinde çok fazla etkisi olmadığı gözlemlenmiştir. Üçüncü veri seti olan Adıyaman ve Şanlıurfa illerini kapsayan mozaiklenmiş SPOT-7 uydu görüntüsü ile Şanlıurfa iline ait Spot-7 verisi, veri boyutundaki alansal ve hacimsel artışın web üzerinden coğrafi veri yayınına etkisini ortaya koyulması amacı ile sıkıştırma süresi, piramitleme süresi ve yayın performansı açısından karşılaştırılmıştır. İlgili karşılaştırma Şekil.4'te verilmiştir. Grafik incelendiğinde veri büyüklüğü ile doğru orantılı olarak sıkıştırma süresi ve piramitleme süresinde artış olmuştur. Şanlıurfa bölgesine ait görüntü ile aynı bölgeye ait mozaiklenmiş veri arasında boyut olarak yaklaşık beş kat fark varken sıkıştırma süresi olarak altı kat, piramitleme süresi olarak dokuz kat fark olduğu tespit edilmiştir.

$\mathrm{Bu}$ sonuçlara bağlı olarak, sıkıştırma ve piramitleme işlem sürelerindeki artışın boyut artışına oranla daha fazla olduğu sonucuna varılmaktadır. Yayın performansı karşılaştırması sonucunda veri boyutu büyüdüğünde performansta yaklaşık \%7 civarında düşüş gözlenmiştir. Üç farklı veri setine göre kıyaslama işleminden bağımsız olarak ham veriler ile yüzde 100 kalitede sıkıştırılıp 9. seviye piramitleme yapılan veriler arasındaki performans ilişkisini ortaya koymak adına 
Şekil.5'teki grafik üretilmiştir. Şekil.5'teki grafik incelendiğinde her bir veri için sıkıştırma ve piramitleme ișlemi yapılan veriler ile ham verilere göre daha yüksek düzeyde yayın performansı gözlemlenmiştir.

Son olarak sıkıştırma ve piramitleme işlemi yapılan görüntülerde görsel kaliteyi tespit etmek amacıyla GAP bölgesini içeren işlenmiş veriler için $\% 60, \% 80$ ve $\% 100$ sıkıștırma seviyelerinde görsel karșılaștırma yapılmıștır. Șekil.6'da karșılaștırmaya ait görsel verilmiştir. Yayınlanan görüntüler incelendiğinde sıkıștırma seviyesine bağlı olarak görsel bir kalite farkı tespit edilememiştir.

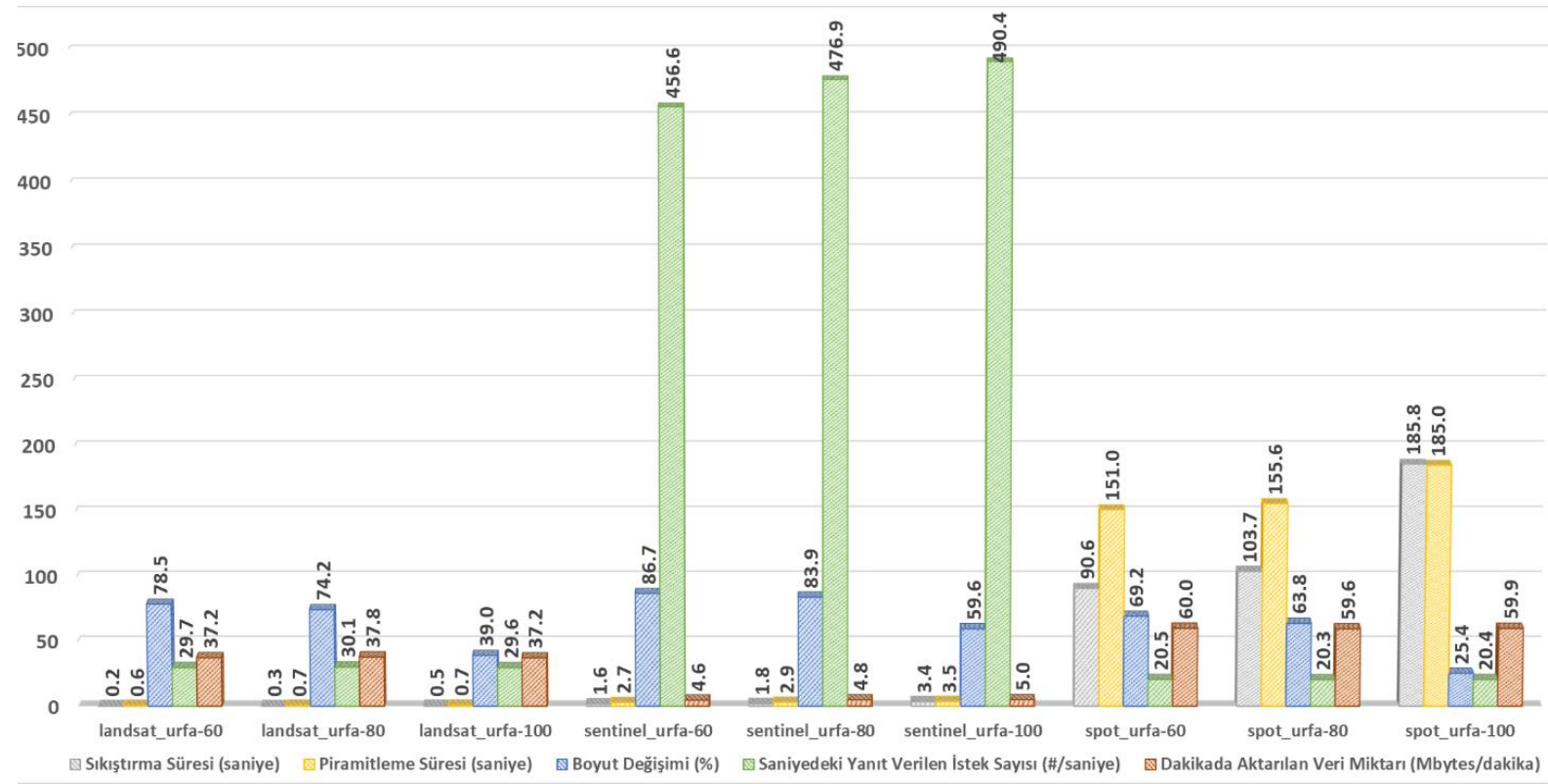

Şekil 2. Çözünürlüğün sıkıştırma, piramitleme ve performansa etkisi

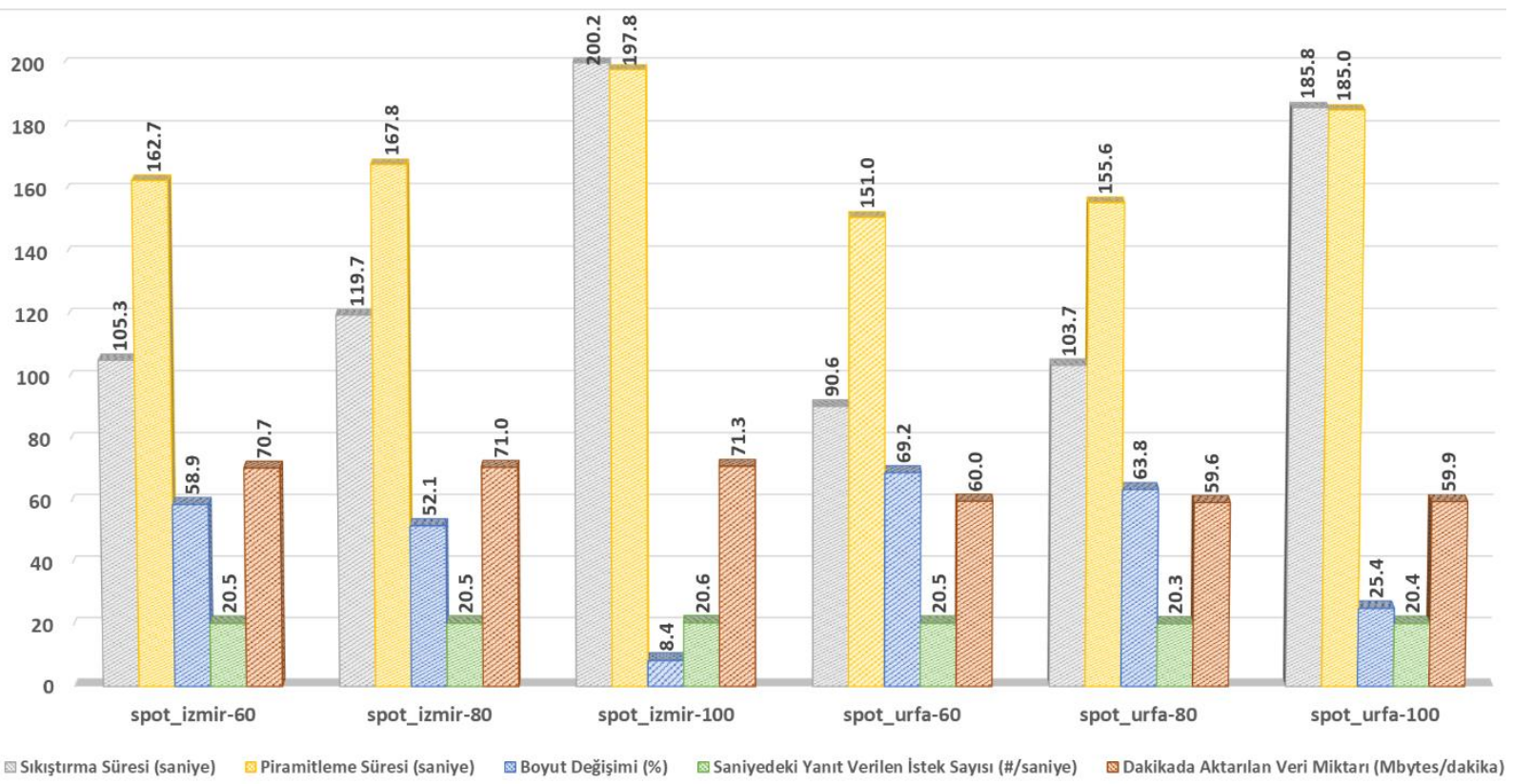

Şekil 3. Farklı arazi örtülerinin sıkıştırma, piramitleme ve performansa etkisi 


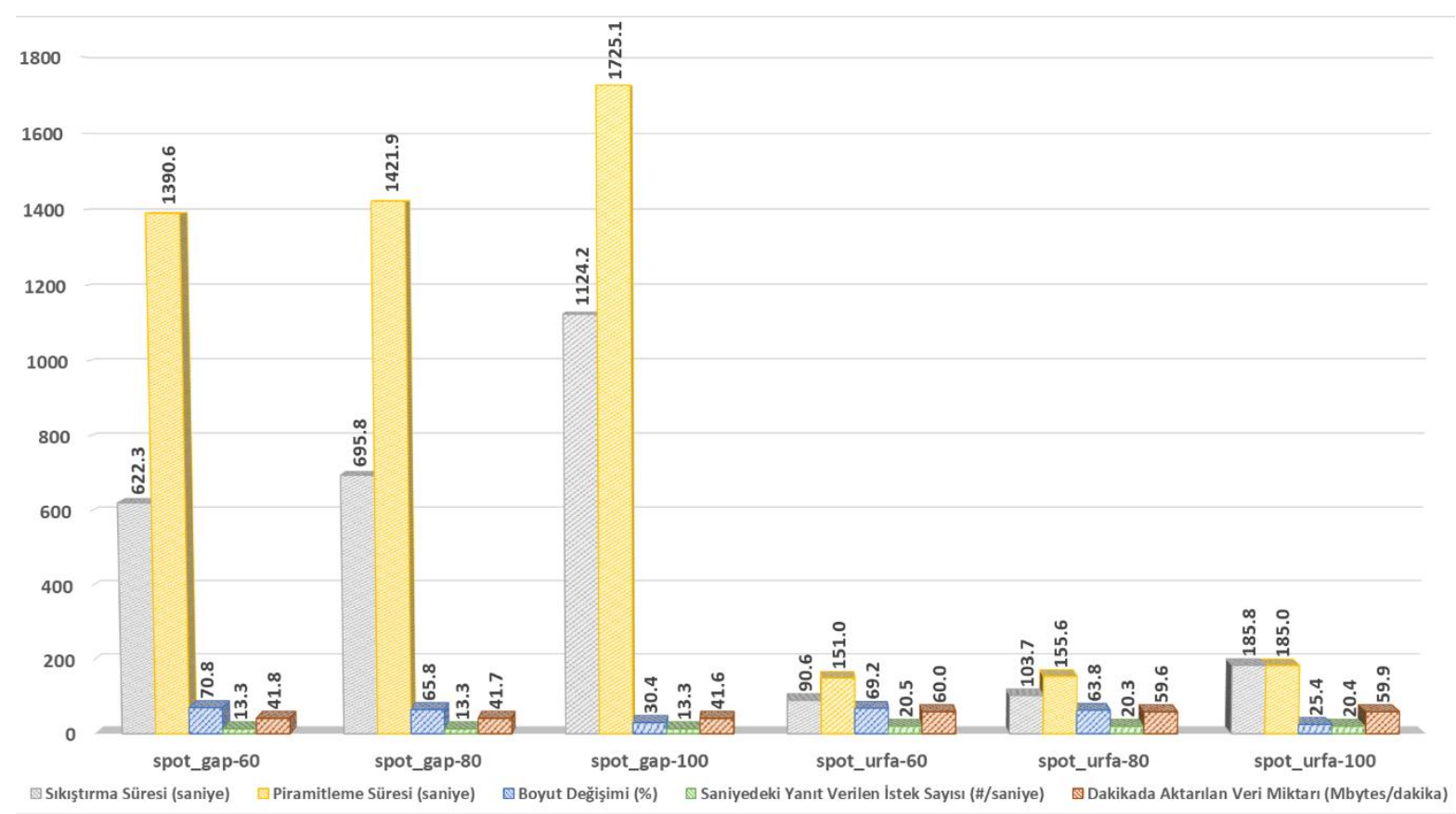

Şekil 4. Veri büyüklüğünün sıkıștırma, piramitleme ve performansa etkisi

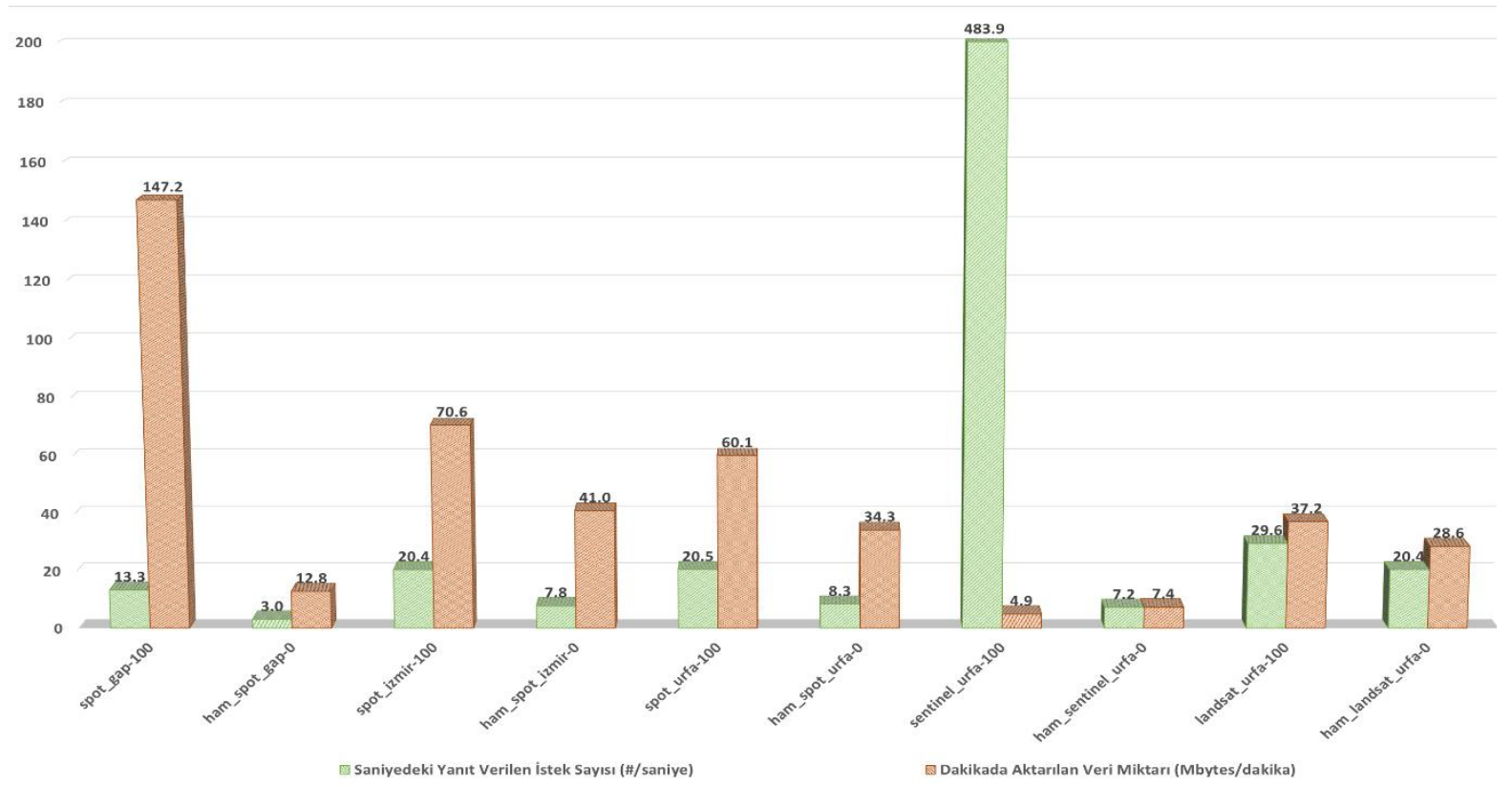

Şekil 5. Ham ve işlenmiş verilerin performans kıyaslaması

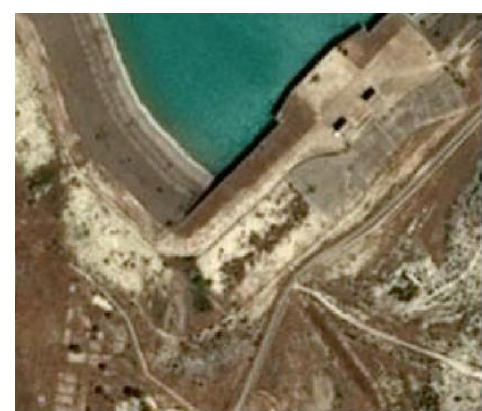

GAP-60

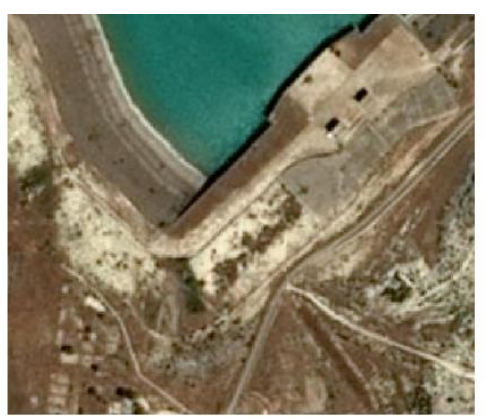

GAP-80

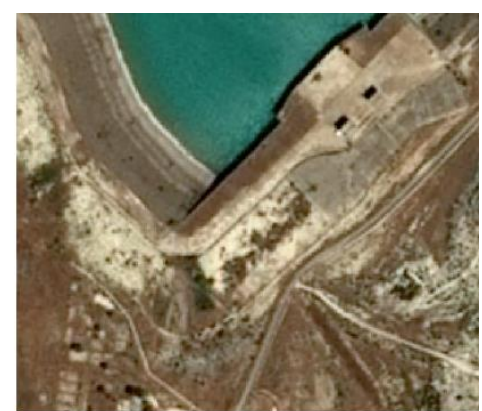

GAP-100

Şekil 6. Çözünürlüğün sıkıştırma, piramitleme ve performansa etkisi 


\section{SONUÇLAR ve TARTIŞMA}

Yapılan çalıșmada üç farklı veri seti için sıkıştırma süresi, piramitleme süresi, boyut üzerindeki değişim ve yayın performansı kapsamında karşılaştırmalar yapılmıştır. Sonuçlar değerlendirildiğinde sıkıștırma süresi ve piramitleme süresi verinin boyutu ile ilişkili olarak değișmektedir. Buna ek olarak sıkıștırma kalitesi, sıkıştırma süresini etkilemektedir. Verilere dayalı olarak bakıldığında sıkıştırma süresi ve piramitleme süresi verinin ne kadar süre içesinde yayına hazır hale geleceği konusunda bilgi vermektedir. Sıkıştırma seviyesi, veri boyutundaki değişimi doğrudan etkilemekte olup, verinin kalitesinin artması durumunda ham veri üzerindeki veri kazancı azalmaktadır. Bu kapsamda veri sıkıștırma seviyesinin yayın kapsamında sunulacak verilerin kalite beklentisi dâhilinde seçilmesi önerilmekle beraber görsel kıyaslamaya dayalı analiz sonuçlarına göre \%60 sıkıștırma seviyesi ve \%100 sıkıştırma seviyesi arasında göz ile görülebilir bir kalite farkına rastlanmamıștır. Sıkıștırılmıș verilere piramit yapısı eklendiğinde oluşan veri boyutları sıkıştırma seviyesine de bağlı olarak ham veriye oranla minimum \%10 kazanç sağlamaktadır. Bununla birlikte sıkıştırılan ve piramit eklenen veriler ile ham veriye kıyasla \%50 civarında performans artışı sağlandığı belirlenmiştir. Yapılan çalıșma sonucunda elde edilen maksimum sıkıştırma seviyesi ve piramit seviyesi ile çalışmaya konu olan uydu verileri özelinde yüksek performanslı ve düşük veri hacimli veri yayını yapılabileceği belirlenmiştir.

\section{KAYNAKÇA}

Hatzopoulos, J., Hatzopoulos, N.J. (2012). Image server to display high resolution satellite images for local planning in the Greek island of Naxos. ASPRS 2012 Annual Conference Sacramento, California, March 19-23, 231-239.

INSPIRE, (2007). Directive 2007/2/EC of the European Parliament and of the Council of 14 March 2007 establishing an Infrastructure for Spatial Information in the European Community (INSPIRE). https://eur-lex.europa.eu/legalcontent/EN/ALL/?uri=CELEX:32007L0002.

Kim M., Kim M., Lee E., Joo I. (2005). Web Services Framework for Geo-spatial Services. In: Kwon YJ., Bouju A., Claramunt C. (eds) Web and Wireless Geographical Information Systems (W2GIS)

Michaelis C., Ames D., (2008). Web Feature Service (WFS) and Web Map Service (WMS). In: Shekhar S., Xiong H. (eds) Encyclopedia of GIS. Springer, Boston, MA.
Millin, G.R., Kitmitto, K. (2007). Satellite Image Data Service - Providing New Geodata Services and Satellite Imagery. GISRUK Conference, NUI Maynooth, Ireland, UK.

Open Geospatial Consortium (OGC), (2016). "DGIWG - Web Map Service 1.3 Profile - Revision" Editors: Stefan Strobel, Dimitri Sarafinof, David Wesloh, Paul Lacey, Published: 2016-01-29.

Panagos, P., van Liedekerke, M., Montanarella, L., Jones, R.J.A., (2008). Soil organic carbon content indicators and web mapping applications. Environemtal Modelling and Software, 23, 1207-1209.

Smiatek, G., (2004). SOAP-based web services in GIS/RDBMS environment. Environmental Modelling \& Software 20 (6), 775e782.

URL1:https://drive.google.com/open?id=170kGW mT31yxBRC4rkE0ZbZ6oBFcukzbC 